\title{
Common Macroeconomic Shocks and Business Cycle Fluctuations in Euro Area Countries
}

\author{
Antonella Cavallo and Antonio Ribba* \\ Università di Modena e Reggio Emilia, Italy
}

\begin{abstract}
This paper investigates the dynamic effects of common macroeconomic shocks in shaping business cycle fluctuations in a group of Euro-area countries. In particular, by using the structural (near)VAR methodology, we investigate the effect of area-wide shocks, with particular attention to monetary policy shocks. The main conclusion is that: (a) contractionary monetary policy shocks cause similar recessionary effects in all countries; (b) as far as business cycle fluctuations are concerned, there is a separation into two distinct groups of countries, with a first group including the biggest European economies in which business cycle fluctuations are mainly explained by common, area-wide shocks and a second one, including Greece, Ireland and Portugal, in which the national shocks play, instead, a much greater role.
\end{abstract}

Key words: Business Cycle Fluctuations; Euro area; Common Shocks;

Near-Structural VARs;

JEL Classification: E31, C32;

Corresponding author: Department of Economics "Marco Biagi" and RECent, Viale Berengario, 51, 41121 Modena, Italy. e-mail: antonio.ribba@unimore.it 


\section{Introduction}

An important question related to the Euro-area economy concerns the possibility that aggregate macroeconomic shocks may exert different effects in specific member countries. In this context, the transmission of monetary policy shocks is, of course, a main concern, given also the existence of a central authority, the European Central Bank (ECB), to which is attributed the task of conducting the monetary policy at the Euro-area level.

In fact, around fifteen years have elapsed from the start of the European Monetary Union (EMU) and hence we begin to dispose of enough data in order to study the influence of ECB's monetary policy choices on the economic activity of Euro area countries.

More generally, in this paper we aim to study the dynamic effects of a small number of macroeconomic shocks, identified at the Euro-area level, in shaping output fluctuations in a group of EMU countries which includes Germany, France, Italy and Spain, i.e. the largest economies of the Euro area, plus Belgium, Greece, Ireland and Portugal. In particular, we want to investigate if the dominant source of macroeconomic fluctuation at the national level is represented by exogenous, Euro-area shocks or, alternatively, by local shocks. Clearly, this is a central question, since in order to allow a smooth functioning of a monetary union, with a central bank conducting its monetary policy at a supra-national level, the convergence of business cycles is of paramount importance.

As stressed by Mihov (2001), even in the presence of a good degree of integration of the national business cycles in the European one, a common monetary policy may fail in stabilizing macroeconomic fluctuations in country members if its effects exhibit heterogeneity across countries.

As far as the conduct of the monetary policy is concerned, it is worth pointing out that since we consider the joint dynamics of a set of national macroeconomic variables and a set of Euro-area macroeconomic variables from the start of the European Monetary Union (EMU), there is no ambiguity in the identification of monetary policy shocks, since there is one single monetary policy regime.

Further, in the specification of the monetary policy equation, concerning the Euro area, we take into account the potential influence exerted by movements in the US Federal Funds Rate. In other words, we allow for the possibility that the Federal Reserve System may exert a significant influence in the conduct of European monetary policy. In reality, this seems a quite reasonable choice since in the first years of EMU both the direction and the magnitude of monetary policy interventions in the Euro area were clearly anticipated by the US central 
bank (cf. Ribba, 2012). Nevertheless, in related research, Scotti (2011) by estimating a non-linear bivariate model concludes that the interdependence of Federal Reserve and ECB does not lead to the conclusion of follower behaviour.

In this paper, we adopt a structural near-VAR approach where the equations for the Euro area include only the lags of Euro-area variables themselves while, as for the national economies, we have full VAR equations. Thus, in general, the near-VAR approach allows a separation of the dynamic system into two (or even more) distinct blocks: a first exogenous block of variables and a second fully endogenous block, with the second one unidirectionally caused by the variables included in the exogenous block. A clear presentation of near-VAR models is given in Doan (2010, chapter 7).

It is worth stressing that an important implication of this approach is that each member country is subject to the same area-wide macroeconomic shocks.

A conclusion of homogeneous effects exerted by common monetary policy shocks in a group of European countries was reached by Peersman (2004), in a investigation concerning the pre-EMU period. Peersman adopted a structural VAR approach. Nevertheless, over the sample period considered by Peersman, 1980 - 1998, the central banks of the European economies were still independent, national institutions. Of course, since they conducted their monetary policy in the EMS fixed exchange rate environment, the policy choices were, at least partially, constrained. Hence, in that economic context, it is not possible to identify a single monetary policy regime.

In a very recent paper, Barigozzi et al. (2013), by using a structural dynamic factor model, obtain instead a result of heterogeneity in the responses of Euroarea countries to ECB decisions. In particular, as far as the responses of prices and unemployment are concerned, they show that there are significant differences between North and South Europe.

To anticipate some conclusions, in the present research we obtain two main results: (a) there is no particular evidence of asymmetric effects of monetary policy shocks since an unexpected monetary tightening causes a recession in all countries; (b) business cycle fluctuations in the biggest European economies are predominantly driven by common, area-wide shocks but, and maybe not surprising, this conclusion does not hold for Greece, Ireland and Portugal.

Thus, our empirical investigation, covering the sample period 1999:1 - 2011:12, seems to support the conclusion that despite their recent, deep macroeconomic imbalances, both Italy and Spain have economic systems characterized by a good macroeconomic integration in the European economy.

It is important to stress that the near-VAR approach utilized in the present research implies the assumption that all the national economies considered in 
the investigation be small open economies interacting in a monetary union, i.e. there is unidirectional, macroeconomic causation (in the Granger sense) running from EMU to national economies. Clearly, at least for the case of Germany, this is a strong and hence easily falsifiable assumption.

We have tried to tackle this potential shortcoming concerning the results for the German economy by also estimating an alternative VAR model in which a full interaction between EMU and German variables is allowed and where the structural area-wide shocks are recovered by imposing sign restrictions. In fact, we find very similar results by comparing the responses of the variables to the monetary policy shock obtained by the two alternative identification strategies and hence we interpret this similarity as an encouraging indication of robustness of the econometric approach adopted in the present research.

The rest of the paper is organized as follows. In section 2 we briefly review some results of (part of) the literature concerning the dynamic effects of macroeconomic shocks in the Euro area.

In section 3 some facts concerning the Eurozone business cycle are presented. In particular, we study the correlations at different leads and lags between the cyclical component of national output and the aggregate, Euro-area cyclical component of output.

Section 4 presents the econometric approach of the paper, based on structural near-VAR models.

In section 5 we show the impulse-response functions concerning the effect of a contractionary monetary policy shock, both at the Euro-area level and at the member-country level. In particular, as for the national economies, we show the dynamic responses of output and inflation to unexpected monetary policy decisions.

In section 6 we investigate on the sources of output fluctuations in member countries. Our results reveal that the Euro-area shocks are the dominant source of output fluctuations at the business cycle frequencies for France, Germany, Italy, Spain and Belgium. Instead, the national shocks mainly explain the variability of output in Greece, Ireland and Portugal.

In section 7 a sensitivity analysis is undertaken: we estimate a VAR model in which the dynamic interaction between the Euro-area variables and the German macroeconomic variables is not restricted. Moreover, the structural shocks are identified by imposing sign restrictions on the response of variables to selected shocks. We find a strong and thus surprisingly similarity with the results obtained by using the structural near-VAR approach.

Section 8 concludes and some policy implications for the Eurozone are also 
drawn.

\section{Macroeconomic heterogeneity in the Euro area: literature sum- mary}

In this area of research, by using structural near-VAR techniques, Peersman (2004) provides empirical evidence on the effects of a common monetary policy shock for seven Euro-area countries. The author concludes that there is similarity in the response of output to monetary shock in the individual countries. The research builds on Peersman and Smets (2001) where a Euro-area structural VAR model was estimated and identified, by using synthetic Euro-area data.

Although Peersman's paper represents an important methodological step forward in comparison to previous investigations, since it identifies a monetary policy shock which is common to individual countries, we have already stressed that it is not possible to isolate a single monetary policy regime for the period of investigation, which covers the sample period 1980 - 1998.

In a more recent paper, Cecioni and Neri (2011) have investigated on possible changes in the monetary transmission mechanism that may have affected EMU after the adoption of the Euro. According to the authors, however, the results obtained by estimating a structural, Bayesian VAR do not provide evidence of a significant change after 1999 .

Instead, by using the sign restrictions approach to VAR identification, Rafiq and Mallick (2008) find that the effects of monetary policy shocks on output in France, Germany and Italy show heterogeneity, since there are significant recessionary effects associated with a contractionary, monetary policy shock only for the case of Germany. However the sample period considered, i.e. 1980 - 2005, poses serious doubts on the possibility to recover a common monetary policy shock, given the existence of national central banks for the greater part of the historical period $1980-2005$.

Weber et al. (2011), by using structural VAR techniques, investigate on possible changes in the transmission mechanism of monetary policy in the Euro area concerning output and inflation. They find two significant break dates, the first in 1996 and the second around 1999. The authors conclude that despite the break points, the estimates show that monetary policy affects prices in the long run while leaving output unchanged. These results, according to the authors, hold for all sub-periods considered ${ }^{1}$.

$\overline{1}$ However, Gerlach and Svensson (2003) conclude that the Eurosystem's moneygrowth indicator, the so-called first pillar in its monetary strategy, does not contain 
Another empirical investigation based on structural VAR models, identified by sign restrictions, is provided by Berg (2012). The author studies the influence on Euro-area stock prices exerted by technology shocks and monetary shocks, respectively. According to Berg, over the period 1995-2003, technology shocks are the main source of fluctuations in real stock prices.

Dedola and Lippi (2005) conducted a more disaggregated investigation at industry level in five OECD countries, including France, Germany and Italy. They use VAR models identified with sign restrictions. Their main result is that the responses to monetary policy shocks are stronger in sectors producing durable goods.

A different methodological approach, in order to investigate the existence of asymmetries in the response of Euro-area countries to common monetary policy shocks, has been recently proposed by Barigozzi et al. (2013). The authors use a Structural Dynamic Factor Model and find that the response of individual countries to ECB decisions exhibits heterogeneity. In particular, as far as the responses of prices and unemployment are concerned, there are significant differences between North and South Europe ${ }^{2}$.

Although there exists a central bank, the ECB, conducting the monetary policy at Euro-area level, an interesting question concerns the possibility of a national bias affecting the members of the Governing Council. This is the subject of a recent investigation undertaken by Hayo and Meon (2013). According to their interpretation, individual members follow national objectives and bargain over the interest rate ${ }^{3}$.

In a very recent research, Georgiadis (2014) tries to provide an explanation of the asymmetries in the monetary transmission mechanism. The author finds that the dominant part of the asymmetries across countries is explained by heterogeneity in financial structures, in labor market rigidities and differences in the industry mix.

An empirical investigation at the regional level has been undertaken by Belke and Heine (2007). The authors aim to study the nexus between changing pat-

much information about future inflation.

2 In this area of research, Carlino and De Fina (1998) proposed one of the first applications of the structural VAR methodology to the investigation of the dynamic effects of monetary policy on regional areas. The authors examined the regional responses to monetary policy in the USA. The main conclusion of their research was that there exists a group of (core) regions exhibiting similar responses. Nevertheless, heterogeneity of effects characterized three non-core regions.

3 A related field of research concerns investigations on the existence of a stable money demand in the Euro area. See, e.g., Artis and Beyer, 2004; Dreger and Wolters, 2010. 
terns of specialisation and changes in the degree of correlation of employment cycles across regions, for a group of Euro-area countries. According to to the authors, their results are consistent with the idea that a common monetary policy may pose problems for uncommon regions within the Eurozone.

Another recent strand of the literature has largely investigated the heterogeneity of inflation rates in Euro-area countries. Indeed, persistent inflation differentials among countries may prevent the smooth functioning of a monetary union. In particular, persistent inflation differentials provoke changes in the relative competitive position of the member countries, with a systematic depreciation in the real exchange rate for countries with inflation below the EMU average and, on the opposite side, real appreciation for those countries with inflation above the EMU average. Hence, this last group of countries will experience persistent foreign trade deficits and a growing external debt ${ }^{4}$.

Moreover, since the ECB sets the level of the short-term interest rate in relation to the average inflation rate of the currency area, those countries experiencing an inflation rate persistently above the average, will receive a procyclical impulse on aggregate demand, via the contraction in the real interest rates ${ }^{5}$.

De Haan (2010) has recently provided a survey of both theoretical and empirical research on the topics of inflation differentials in EMU.

A recent paper by Cavallo and Ribba (2014) concludes that Euro-area inflation should be a predictor, in other words an anchor, for national inflations. However, this result holds only for a small group of countries, including France and Italy.

Although in the context of an empirical investigation concerning the law of one price, a result of increasing convergence for France is also obtained by Martin and Mejean (2013). The main finding of their study is that the monetary union has significantly improved the convergence of French export prices towards Euro-area countries.

Summing up: it seems that, at this stage, the empirical research concerning the

4 According to Honohan and Lane (2003), there is evidence that in the first years of the euro an important factor influencing inflation differentials in the European economies was represented by exchange rate effects. However, they also present evidence of a limited role exerted by the Balassa-Samuelson effect in explaining inflation differentials.

5 The risk of destabilizing pro-cyclical dynamics induced by the monetary policy choices in a fixed exchange rate regime was raised by Alan Walters in the 1980s, in the context of the European Exchange Rate Mechanism. See, for example, Walters (1988). 
Euro area is still far from a shared conclusion on the existence of heterogeneity in the dynamic effects of area-wide shocks on member countries.

\section{Some facts concerning business cycle fluctuations in the Euro area}

Although the main aim of this empirical research is to investigate the potential presence of heterogeneity in the business cycle fluctuations affecting the Euro-area countries by using structural VAR techniques, in this section, as a preliminary statistical analysis, we summarize some descriptive information for the period 1999:1-2011:12, concerning the co-movement between: (1) national output and Euro-area output (table 1); (2) national inflation and Euro-area inflation (table 2).

We consider the Euro-area industrial production as an indicator of the aggregate Eurozone output and, of course, the same indicator of the aggregate output is selected at the country level. In particular we obtain a measure of the cyclical component of output by applying the Hodrick-Prescott filter to the variables.

As shown in table 1, as far as output cross correlations are concerned, there is a strong co-movement which characterized, at various leads and lags, a group of countries including Germany, France, Italy, Spain and Belgium. Instead, the co-movement is weaker for another group of Euro-area countries, including Portugal, Greece and Ireland.

The strength of the correlations is far from surprising for France, Germany and Belgium but the relevant co-movement with the cyclical component of European output characterizing both Italy and Spain might surprise, since these countries are often identified as members of the "Mediterranean" group, affected by macroeconomic heterogeneity with respect to the German, "Nordic" block.

\section{Insert Table 1 about here}

In table 2 cross correlations between national and Eurozone inflation are shown. The annual inflation rate, based on the HCPI index, both for the Euro area and for the member-countries, is our selected measure of inflation.

Although the results are similar to those shown in the previous table, it is worth noticing that the linkages concerning the national inflation rates seem to be (relatively) stronger in the Euro area.

However, in a very recent paper, Cavallo and Ribba (2014) have investigated 
the inflation differentials in the Eurozone countries. By using cointegration techniques, they conclude that only a small group of countries exhibit stable fluctuations of the national inflation rate around the aggregate, Euro-area average inflation rate.

Of course, some further step forward is required in order to give a more structural interpretation of the correlations presented in this section. We will make this step in the next sections, by estimating and identifying a structural VAR model which allows both a separation among area-wide and national shocks and an evaluation of the relative importance of local shocks in causing business cycle fluctuations in the national economies.

\section{Insert Table 2 about here}

\section{The approach of the paper}

In this paper we estimate, by using monthly data for the period 1999:12011 : 12, a near-VAR in order to model the dynamic interaction between Euro-area countries ${ }^{6}$ and the Euro-area aggregate level. More precisely, we start with the estimation of the following near-VAR model:

$$
\left(\begin{array}{c}
\pi_{t} \\
y_{t} \\
i_{t}-i_{t}^{*} \\
\epsilon_{t} \\
\pi_{i t} \\
y_{i t}
\end{array}\right)=\left(\begin{array}{cccccc}
A_{11}(L) & A_{12}(L) & A_{13}(L) & A_{14}(L) & 0 & 0 \\
A_{21}(L) & A_{22}(L) & A_{23}(L) & A_{24}(L) & 0 & 0 \\
A_{31}(L) & A_{32}(L) & A_{33}(L) & A_{34}(L) & 0 & 0 \\
A_{41}(L) & A_{42}(L) & A_{43}(L) & A_{44}(L) & 0 & 0 \\
A_{51}(L) & A_{52}(L) & A_{53}(L) & A_{54}(L) & A_{55}(L) & A_{56}(L) \\
A_{61}(L) & A_{62}(L) & A_{63}(L) & A_{64}(L) & A_{65}(L) & A_{66}(L)
\end{array}\right)\left(\begin{array}{c}
\pi_{t-1} \\
y_{t-1} \\
i_{t-1}-i_{t-1}^{*} \\
\epsilon_{t-1} \\
\pi_{i t-1} \\
y_{i t-1} \\
{[1]}
\end{array}\right)+\left(\begin{array}{c}
e_{1 t} \\
e_{2 t} \\
e_{3 t} \\
e_{4 t} \\
e_{5 t} \\
e_{6 t}
\end{array}\right)
$$

The estimated model is thus divided into two blocks. The first block includes the following variables: the Euro-area annual rate of inflation, based on the HICP index, $\pi_{t}$; the cyclical component of the Euro-area industrial production, $y_{t}$, obtained by applying the Hodrick-Prescott filter; the differential between the European overnight interest rate (Eonia), $i_{t}$, and the US federal funds rate, $i_{t}^{*}$; the nominal exchange rate, $\epsilon_{t}$, defined as US dollars per currency unit $^{7}$.

6 For Greece the estimation period is 2001:1 - 2011:12

7 Data concerning the Federal Funds rate and the nominal exchange rate are 
Thus, we take the short-term interest rates as measuring the stance of monetary policy (see, e.g. Bernanke and Mihov, 1998 and Taylor, 1999).

More precisely, we specify a reaction function of the monetary authority in the Euro area, i.e. the ECB, in terms of a monetary rule for an open economy. Indeed, there is clear evidence of a significant interaction between the ECB and the Federal Reserve System in the first fifteen years of EMU (cf. Ribba, 2012).

The second block instead includes the macroeconomic variables at the national level: the annual rate of inflation of the country $i, \pi_{i t}$, based on the HICP index; the cyclical component of the industrial production of the country $i$, $y_{i t}$, obtained by applying the Hodrick-Prescott filter.

We estimate a VAR model including all variables in levels and thus we do not search either for unit roots or for the existence of long-run equilibrium relations, i.e. for cointegration. Nevertheless, it is worth noticing that we include in the estimated VAR the cyclical component of both the national and the Euro-area output, i.e. we take the stationary component of total output. Moreover, as far as the interest rate is concerned, it is worth recalling that we specify the variable in relative terms, i.e. as the differential between the short-term Euro-area, nominal interest rate and the US federal funds rate.

Although we are aware that the inflation rate may exhibit a unit root, the strong commitment of the central bank towards price stability in the last decade or, more precisely, towards a low and stable inflation rate ("close but below two percent") may justify our assumption of stationarity, even for this variable.

More generally, we must add that given the short sample period and the (relatively) large numbers of variables included in the near-VAR model, the selection of long run equilibrium relations and, moreover, the complete identification of the cointegration space would be a very difficult task.

Summing up: deriving impulse responses from a VAR in levels seems to be, in the context of the present empirical investigation, a proper choice.

In the presence of a near-VAR system, OLS gives consistent estimates. How-

obtained from the FRED database: http://research.stlouisfed.org/, Overall inflation for the Euro area is obtained from the Harmonized Consumer Price Index (HCPI). The series concerning the HCPI, the industrial production for the Euro area and the corresponding national variables were taken from the Eurostat site: ec.europa.eu/eurostat.

Instead, the series for the Eonia rate was taken from the ECB web site, at http://www.ecb.int/stats/ 
ever, some potential gain comes from estimation of the system using SUR, Seemingly Unrelated Regressions (cf. Zellner 1962) and hence, in estimating system [1], we use SUR methods. As for lag length selection, both the Schwartz and the Akaike criteria suggest one lag for the estimated VARs.

We stress that an important advantage of this specification descends from the consideration that although we estimate for each country a separate VAR system which allows the joint dynamics between area-wide variables and the national ones to be modeled, the set of aggregate Euro-Area shocks is identical for all countries. In other words, this near-VAR specification ensures a property of invariance for the common macroeconomic shocks affecting the national variables.

By collecting the variables included in system [1] in the $1 \times 6$ vector:

$$
X_{t}^{\prime}=\left(\begin{array}{llllll}
\pi_{t} & y_{t} & i_{t}-i_{t}^{*} & \epsilon_{t} & \pi_{i t} & y_{i t}
\end{array}\right)
$$

and by indicating with $e_{t}$ the $6 \times 1$ vector of error terms, such that $E\left(e_{t}\right)=0$ and $E\left(e_{t} e_{t}^{\prime}\right)=\Sigma_{e}$, we can write the following reduced-form moving average representation of the near-VAR:

$$
X_{t}=C(L) e_{t}
$$

where $C(0)=I$.

We recover the structural shocks at the Euro-Area level and at the national level by imposing a (contemporaneous) recursive structure to the estimated near-VAR model. Hence, the structural moving-average representation is given by:

$$
X_{t}=B(L) \eta_{t}
$$

Where $B(L)=C(L) B$ and $\eta_{t}=B^{-1} e_{t} . B$ is the Cholesky factor of $\Sigma_{e}$, i.e. is the unique lower triangular matrix such that $B B^{\prime}=\Sigma_{e}$.

The economic interpretation of this set of identifying restrictions is that, as for the block of Euro-Area variables, a monetary policy shock does not influ- 
ence within the period (one month) either inflation or industrial production. In turn, a demand shock exerts a delayed effect on inflation. Moreover, the exchange rate does not exert a contemporaneous effect on the differential between Eonia and the federal funds rate and on the other Euro-area variables.

Such an orthogonalization of the structural shocks is widely adopted in the literature studying the dynamic effects of monetary policy shocks (see, for example, Eichenbaum and Evans, 1995). We must add that, at least in our opinion, using zero contemporaneous restrictions in order to obtain exact identification of the model, in the context of sample data at monthly frequencies, imposes a lesser strait jacket on data than in the cases with quarterly or annual data.

As far as the national block is concerned, the imposed causal structure implies that a local aggregate demand shock does not exert a contemporaneous effect on the national inflation.

However, as an exercise of robustness of both the identification strategy and the assumption that the Euro-area block is independent of national variables, in a next section of the paper we also recover the structural shocks affecting the Euro-area block and the German variables block, in an alternative way, by using sign restrictions.

In order to get the impulse response functions with the confidence bands, we utilize Monte Carlo integration and Gibbs sampling. The Gibbs sampler is a particular technique recently developed to tackle situations in which it is not possible to make direct draws based on random Normals (see Doan, 2010).

\section{Estimation results: the responses of variables to monetary shocks}

We have organized the set of impulse-response functions in three figures. In figure 1 we report the response of the Euro-area macroeconomic variables to a contractionary monetary policy shock. Instead, figures 2 and 3 show the responses of national variables, respectively, output and inflation, to the contractionary monetary policy shock.

Median responses are reported together with the error bands. In the spirit of Sims and Zha (1999) we consider the 16th and the 84th percentiles.

As shown in figure 1, a monetary tightening provokes a recession in the Euro area, since there is a significant contraction of both the output and the inflation rate for about three years following the tightening.

It is worth noting that the identifying restrictions impose the absence of con- 
temporaneous effects, i.e. within the month, of the exogenous monetary policy shock on inflation and output. More precisely, in order to recover the structural shocks, we have imposed a recursive, causal structure. However, despite this identification strategy, the response of inflation is not plagued by the puzzling, wrong sign which often affects structural VAR analysis of monetary policy. In particular, the wrong sign in the response of price usually characterizes structural VARs in which shocks are recovered by imposing Wold causal orderings (see e.g. Christiano et al. 1999).

On the other hand, we find that in response to the contractionary monetary policy shock there is a small reaction in the exchange rate in the first months following the shock. Further, the appreciation exhibits persistence. Thus, the response exhibits a correct sign but the persistent appreciation of the national currency is at odds with the Uncovered Interest Parity (UIP). For, if UIP holds, then an increase in the domestic rate with respect to the foreign rate should cause an appreciation of the national currency followed over time by a movement of opposite sign. The persistent appreciation of the national currency in response to a monetary tightening is another known result in the structural VAR approach based on contemporaneous restrictions literature, at least since the works by Eichenbaun and Evans (1995) and by Grilli and Roubini (1996). More recently, Scholl and Uhlig (2008) have applied the sign restrictions methodology to the exchange rate responses to monetary policy shocks and have found that a persistent appreciation remains a feature of the data.

\section{Insert Figure 1 about here}

Figure 2 collects the responses of inflation and output to the monetary policy shock for the major Euro-area economies. The remarkable result is that there are no appreciable differences in the timing and in the profile of the responses among countries. Instead, as far as the size of the response of national output is concerned, some differences arise. For, as shown in table 1, a one point percentage increase in the differential between the Eonia rate and the federal funds rate causes a negative, maximum effect on German output of 1.82 and a maximum effect on French output of -.96 (for Italy and Spain the values are, respectively, -1.48 and -1.27$)$.

\section{Insert Figure 2 about here}

In figure 3 the results for the other four countries are reported. The recessionary effects of the common monetary policy shock are confirmed as well as, also for these countries, the contractionary effects exerted on the inflation rate. 


\section{Insert Figure 3 about here}

It is worth noticing that for Greece, Ireland and Portugal the maximum effect of monetary policy on output is less than one for one.

We stress that the comparison of the responses of national output to the contractionary monetary shock is legitimate, since the member-countries face a common exogenous monetary policy shock which exhibits the same size for all. However, in order to make it easier to grasp the dispersion of the responses across countries, we have also reported in one single figure (cf. figure 4) the whole set of national responses of output to the common monetary policy shock. Visual inspection confirms the similarity of the national responses. Nevertheless, we must stress that, in this context, we are not assessing similarity and asymmetries through formal statistical tests.

\section{Insert Table 3 about here}

\section{Insert Figure 4 about here}

In section 7 we aim to undertake an exercise in robustness, identifying the common monetary policy shock by sign restriction. However, as a first exercise, we have re-estimated the near-VAR model of this section separating in two distinct equations the European overnight rate and the federal funds rate. To save space, we only report, in figure 5, the responses of Euro-area variables and German variables to the contractionary monetary policy shock. Indeed, in the light of the results obtained, it seems there is great similarity with the dynamic responses obtained by specifying a reduced-form open economy monetary policy rule. 


\section{Estimation results: the dominant sources of fluctuations in mem- ber countries}

By using the structural representation [3], it is possible to build the error in forecasting $X_{t}$ for each horizon $k$ :

$$
X_{t+s}-E_{t} X_{t+s}=B_{0} \eta_{t+s}+B_{1} \eta_{t+s-1}+B_{2} \eta_{t+s-2}+\ldots .+B_{s-1} \eta_{t+1}
$$

From [4] and given the orthonormality of the structural disturbances, the variance of the forecasting error is:

$$
\operatorname{Var}\left(X_{t+s}-E_{t} X_{t+s}\right)=B_{0} B_{0}^{\prime}+B_{1} B_{1}^{\prime}+B_{2} B_{2}^{\prime}+\ldots .+B_{s-1} B_{s-1}^{\prime}
$$

From this formula, it is possible to decompose the total variance of the forecast error, for each variable, which is ascribable to the variance of each structural shock. In particular, we would like to use equation [5] to answer the following question: is the dominant source of variability in domestic output attributable to the set of common, area-wide shocks or, alternatively, do the local, specific structural shocks explain much of the variability of the national output? This amounts to investigating the degree of integration of the national business cycles into the European one.

According to the results shown in table 2, there are two distinct groups of countries: the first, which includes Germany, France, Italy, Spain and Belgium, is characterized by a dominant role played by Euro-area structural shocks in composing the variability of the national outputs; the second group, including Greece, Ireland and Portugal in which the relative importance of local, structural shocks is dominant at different horizons with respect to Euro-area common macroeconomic shocks.

Although Italy, Spain and Belgium start with a higher importance of local shocks in comparison to France and Germany, there is a quick convergence, in around 12 months, to a weight of the Euro-area common shocks which is on average 80 percent for the three countries.

The case for Greece, Ireland and Portugal is quite different: even after seven years, the majority of the variability in national output is largely explained by the sum of the local, specific shocks. 
As a whole, these results tell us that Italy and Spain, despite their macroeconomic imbalances, exhibit business cycle fluctuations which are integrated in the European business cycle. Instead, for Greece, Ireland and Portugal the dominant presence of asymmetric shocks is still a significant problem, 15 years from the start of EMU.

\section{Insert Table 4 about here}

One might wonder if the analysis conducted at the aggregate, national level be capable of obscuring a more remarkable regional heterogeneity still affecting the Euro area. For example, a study in this spirit is due to Belke and Heine (2007). In our opinion, further investigation at a more disaggregated, regional level, even by using the structural VAR techniques of the present paper, could represent a future step worth undertaking.

\section{An alternative identification strategy based on sign restrictions}

The near-VAR specification presented in the previous sections has some advantages, in the context of the present investigation, with respect to traditional VAR models specification. In particular we have stressed the main strong point of this approach, which is associated with the invariance of the common area-wide shocks affecting the national economies.

Nevertheless, a potential weakness of this methodology consists in treating all the EMU member-countries as small open economies. Clearly, this choice might fit well to Greece or Ireland but is highly questionable, for example, for France and above all for Germany.

Thus, in this section we undertake a sensitivity analysis and estimate a VAR model including the variables of the exogenous block in system [1] jointly with inflation and output for the German economy. First, we estimate a traditional, reduced-form VAR model, i.e. in this case the estimation of the equations for the Euro-area variables also include lags of German variables. Then we proceed to the identification of a contractionary monetary policy shock by imposing sign restrictions on the responses of (some) variables (cf. Faust, 1998; Canova and De Nicoló, 2002; Uhlig 2005).

A presentation of the sign restrictions approach, in the context of a discussion of alternative identification schemes, is given in Canova (2007, chapter 4).

The logic behind this sensitivity analysis is the following: if in the case of Germany, i.e. the biggest Euro-area country member, the results obtained by imposing sign restrictions in a traditional VAR specification were not so 
different from those obtained in the near-VAR specification then, a-fortiori, this result can be interpreted as an encouraging indication of robustness for the empirical results obtained in the first part of this paper for all the European countries included in the investigation.

In the first step we estimate the following reduced form of a VAR model of order 1:

$$
X_{t}=A_{1} X_{t-1}+e_{t}
$$

where vector $X_{t}$ includes the four endogenous variables related to the Euro area, i.e. inflation, output, the differential between the Eonia rate and the federal funds rate, and the exchange rate, and the two German variables, i.e. inflation and output. The covariance matrix of the vector of residuals, $e$, is given by $\Sigma_{e}$.

In the second step, the matrix $\Sigma_{e}$ is randomly drawn from the posterior distribution of the matrix of the VAR coefficients. In the structural VAR approach, the relation between the error terms, $e_{t}$, and the exogenous macroeconomic shocks, $\epsilon_{t}$, is given by: $e_{t}=F \epsilon_{t}$. The sign restrictions method proposed by Uhlig (2005), given $F F^{\prime}=\Sigma_{e}$, aims to identify an impulse vector, $f$, such that $f=F \alpha$, where $\|\alpha\|=1$, which is consistent with some standard macroeconomic theory. The minimal set of restrictions imposed by this approach implies that there exists a space of impulse vectors consistent with the chosen macroeconomic model. However, in order to select a unique impulse vector, it is possible to introduce a penalty function. In this investigation we use a penalty function which is similar to the one introduced by Uhlig ${ }^{8}$ (2005).

In particular, in order to identify the monetary policy shock, we impose a negative response of Euro-area inflation to a contractionary monetary policy shock. More precisely, we impose a negative response of inflation for a period of three months to a unexpected increase in the differential between the Eonia rate and the federal funds rate. Instead, the responses of the Euro-area output and of the exchange rate are left free. Moreover, we do not impose restrictions on the responses of German variables.

As shown in figure 4, a contractionary monetary policy shock causes a recession both in the Euro area and in Germany. Further, there is a persistent decrease in inflation. However, the really surprising result is that both the response profile of impulse-response functions and the size of the dynamic effects of the monetary shock, are very similar to those obtained by using the near-VAR

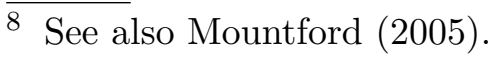


specification and the recursive structure strategy to recover the structural shocks.

Undoubtedly, another implication of this result is that the recursive assumption adopted to identify the set of structural shocks, and in particular the monetary policy shock, in the context of the near-VAR specifications of sections 4 and 5, does not impose an excessive strait jacket on data.

\section{Insert Figure 6 about here}

In the light of the results presented in this section, as a subject of future research it could be interesting to isolate a general set of conditions under which a recursive, causal structure (cf. Sims 1980) and a sign restrictions approach generate shocks which cause identical responses in some variables; of course, identical responses except for the zero restrictions imposed in the causal structure.

\section{Conclusion and some policy implications}

In this research, by using structural VAR techniques, we have identified a set of common, and invariant, macroeconomic shocks at the Euro-area level and then we have studied their effects on national output and inflation for a group of EMU countries.

The results obtained in the present investigation reveal that macroeconomic heterogeneity is still alive in EMU: fifteen years after the outset of the Monetary Union, a group of countries including Greece, Ireland and Portugal exhibits output fluctuations dominated by national, local shocks rather than by Euro-area, common shocks.

The five other member countries included in the present investigation, i.e. Belgium, France, Germany, Italy and Spain, instead show a good integration in the Euro-area business cycle, since the variability of their national output is dominated at the different frequencies by area-wide, macroeconomic shocks.

Thus, despite the detection of relevant asymmetries still affecting the Eurozone, the results of our investigation do not support the idea of a pure separation of the Euro area into two distinct blocks: a homogeneous German block, maybe including France, and another, homogeneous Mediterranean block, characterized by business cycle fluctuations not well integrated in the business cycle fluctuations of the German block. In fact, this separation may turn out unfruitful in studying the European economy since the empirical analysis undertaken in the present article shows that Italy and Spain are indeed 
well integrated in the European business cycle. Moreover, we also suspect that future research might show that further adjustments in the Euro-area countries, concerning asymmetries and imbalances, might have been carried on in more recent years.

We add that in the light of the results shown on Euro-area business cycle, the interpretation of coalition votes in the ECB Coucil, with the consolidated dialectics between a North group of governors and a South one, should not be related to a general problem of macroeconomic heterogeneity in the Euro area but, rather, to potential contrasting views (and, maybe, interests) concerning the public debt policy in the Euro area and, as a strictly related problem, the monetary policy choices by the ECB.

Nevertheless, more encouraging results for the economic and monetary integration in the Euro area come from the conclusion that the ECB's decisions on the short-term interest rates transmit their effect in a relatively homogenous way to all the member countries included in the present empirical analysis.

More precisely, we find that a contractionary monetary policy shock pushes into recession all the eight economies and causes a significant decrease both in output and inflation for around three years. Nevertheless, the response of the national variables to the monetary shock seems to be more pronounced in Belgium, Germany, Italy and Spain, since in these countries an increase of 100 basis points in the short-term interest rate provokes a negative, maximum effect on output ranging between 1.27 and 1.82 percent.

Thus, the good news is that ECB's monetary policy choices are effective for all the Euro-area countries included in the present study. Moreover, it seems that the results obtained in our investigation are consistent with the idea that structural reforms should also be pursued in countries affected by low potential growth and by structural macroeconomic imbalances. However, in the current economic environment characterized by persistent recession in the Eurozone and by deflation, in particular in the Mediterranean countries, such policies are needed in conjunction with expansionary monetary policy pursued by the ECB and, more generally, with macroeconomic policies at the Euro-area level aiming to a rebalancing of the aggregate demand from economies with saving gluts (e.g. Germany).

In the context of an analysis of the role of macroeconomic policies in the global crisis, such a position has been supported by Catte et al. (2011), among others. On an opposite side, Belke et al. (2014) have recently maintained that the steps towards the Quantitative Easing, taken by the ECB in recent months, could be a move towards a policy of unlimited financing of the public debt which exhibits the potential risk of threatening price stability over the long term. 


\section{Acknowledgements}

We wish to thank the Editor, Hamid Beladi, and the two anonymous referees for very useful comments and suggestions which improved the paper. We also thank Pietro Dallari and seminar participants at the International Conference of Economic Modeling, Bali, Indonesia, July 2014, for their comments on a previous version of this research.

\section{References}

[1] Artis, M. \& Beyer, A. (2004). Issues in Money Demand. The case of Europe. Journal of Common Market Studies, 42, 717 - 736.

[2] Barigozzi, M., Conti, M. \& Luciani, M. (2014). Do Euro Area Countries Respond Asymmetrically to the Common Monetary Policy? Oxford Bulletin of Economics and Statistics, 76, 693- 714

[3] Belke, A. and Heine, J. (2007). On the Endogeneity of an Exogenous OCACriterion: Specialization and the Correlation of Regional Business Cycles in Europe. Empirica 34, 15 - 47.

[4] Belke, A., Freytag, A., Keil, A. \& Schneider, F. (2014). The Credibility of Monetary Policy Announcements: Empirical Evidence for OECD Countries since the 1960s. International Review of Economics and Finance, 33, $217-227$.

[5] Berg, T. (2012). Did Monetary or Technology Shocks Move Euro Area Stock Prices? Empirical Economics, 43, 693 - 722.

[6] Bernanke, B.S. \& Mihov, I. (1998). Measuring the Monetary Policy. Quarterly Journal of Economics, 113, 869 - 902.

[7] Canova F (2007). Methods for Applied Macroeconomic Research. Princeton University Press.

[8] Canova, F. \& De Nicolo', G. (2002). Monetary Disturbances Matter for Business Fluctuations in the G-7, Journal of Monetary Economics, 49, 1131 - 1159.

[9] Carlino, G. \& DeFina, R. (1998). The Differential Regional Effects of Monetary Policy. Review of Economics and Statistics, 80, 572 - 587.

[10] Catte, P., Cova, P., Pagano, P. Visco, I. (2011). The role of macroeconomic policies in the global crisis. Journal of Policy Modeling, 33, $787-803$.

[11] Cavallo, A. Ribba, A. (2014) Euro Area Inflation as a Predictor of National Inflation Rates. Journal of Policy Modeling, 36, 1048 - 1065.

[12] Cecioni, M. \& Neri, S. (2011). The Monetary Transmission Mechanism in the Euro Area: Has it Changed and Why? Economic Working Papers 808, Bank of Italy. 
[13] Christiano, L. Eichenbaum, M. \& Evans CL (1999). Monetary Policy Shocks: What Have We Learned and to What End? in J.B. Taylor and M.Woodford, Eds., Handbook of Macroeconomics, North Holland, Amsterdam, pp. 65-148.

[14] de Haan, J. (2010). Inflation differentials in the Euro Area: A survey. In de Haan J., Berger H. The European Central Bank at Ten, Springer.

[15] Dedola, L. \& Lippi, F. (2005). The Monetary Transmission Mechanism: Evidence from the Industries of 5 OECD Countries. European Economic Review, $49,1543-1569$.

[16] Doan, T.A. (2010). RATS User's Manual, Version 8, Estima, 1560 Sherman Avenue, Suite 510, Evanston, IL 60201.

[17] Dreger, C. \& Wolters, J. (2010). Investigating M3 Money Demand in the Euro Area, Journal of International Money and Finance, 29, 111 - 122.

[18] Eichenbaum, M. \& C. L. Evans (1995). Some Empirical Evidence of Shocks to Monetary Policy on Exchange Rates, Quarterly Journal of Economics, 110, $975-1010$.

[19] Faust, J. (1998). The Robustness of Identified VAR Conclusions about Money, Carnegie-Rochester Conference Series on Public Policy, 49, 207 - 244.

[20] Gerlach, S. \& Svensson, L.O.E. (2003). Money and Inflation in the Euro Area: a Case for Monetary Indicators? Journal of Monetary Economics, 50, 1649-1672.

[21] Georgiadis, G. (2014). Towards an Explanation of Cross-country Asymmetries in Monetary Transmission. Journal of Macroeconomics, 39, $66-84$.

[22] Grilli, V. \& Roubini, N. (1996). Liquidity Models in Open Economies: Theory and Empirical Evidence. European Economic Review, 40, 847 - 859.

[23] Hayo, B. \& Meon, P-G. (2013) Behind Closed Doors: Revealing the ECBs Decision Rule. Journal of International Money and Finance, 37, 135 - 160.

[24] Martin, J. \& Mejean, J. (2013). Price Dispersion and the Euro: Micro Heterogeneity and Macro Implications. International Review of Economics and Finance, 26, $70-86$.

[25] Mihov, I. (2001). Monetary Implementation and Transmission in the European Monetary Union. Economic Policy, 33, 370 - 160.

[26] Mountford, A. (2005). Leaning into the Wind: A Structural VAR Investigation of UK Monetary Policy. Oxford Bulletin of Economics and Statistics, 67, $597-$ 621.

[27] Peersman, G., (2004). The Transmission of Monetary Policy in the Euro Area: Are the Effects Different Across Countries? Oxford Bulletin of Economics and Statistics, 66, $285-308$. 

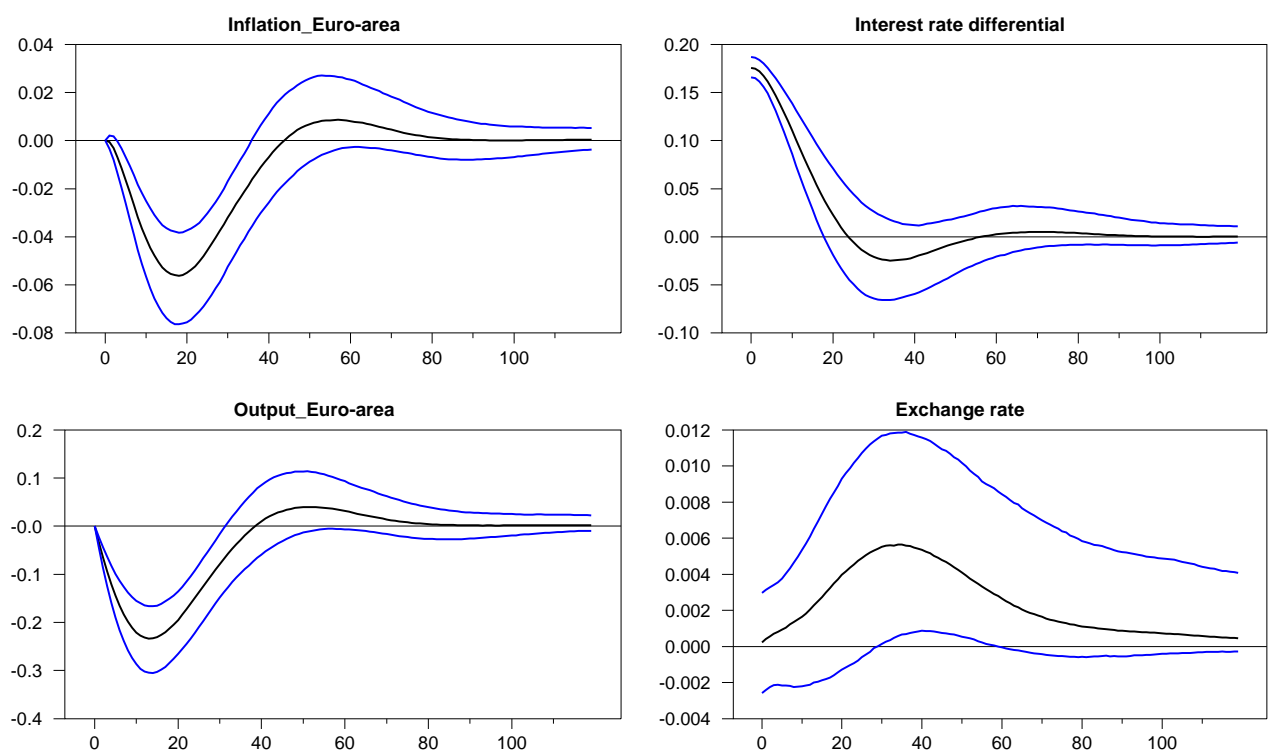

Responses to Monetary Policy Shock:Euro Area

FIGURE 1: Impulse-response functions for the Euro Area: response of output, inflation, interest rates and exchange rate to a contractionary monetary policy shock. 

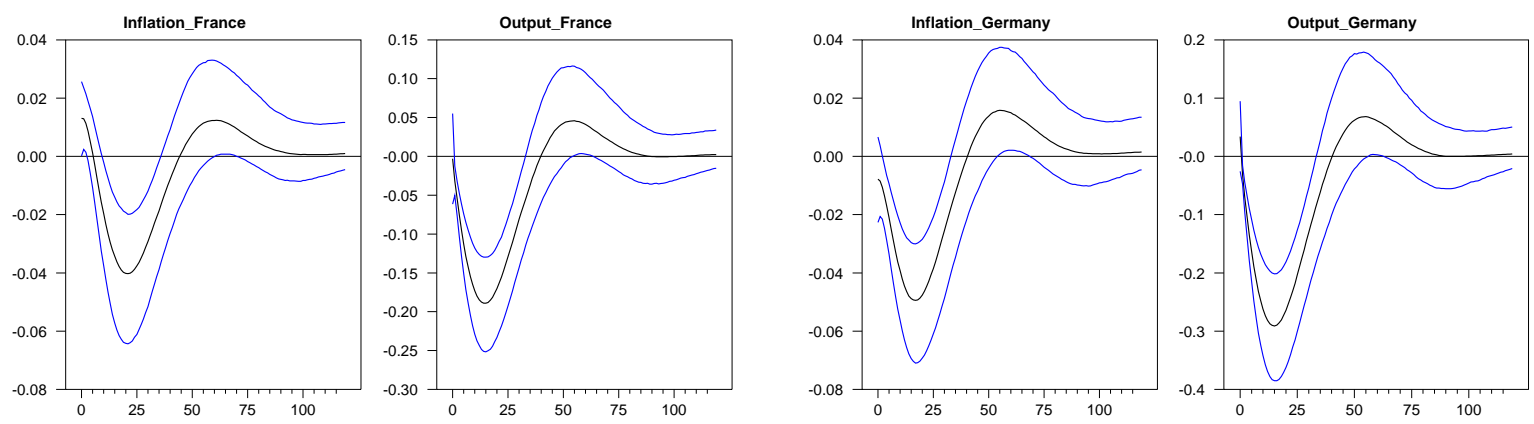

Responses to Monetary Policy Shock:France

Responses to Monetary Policy Shock:Germany
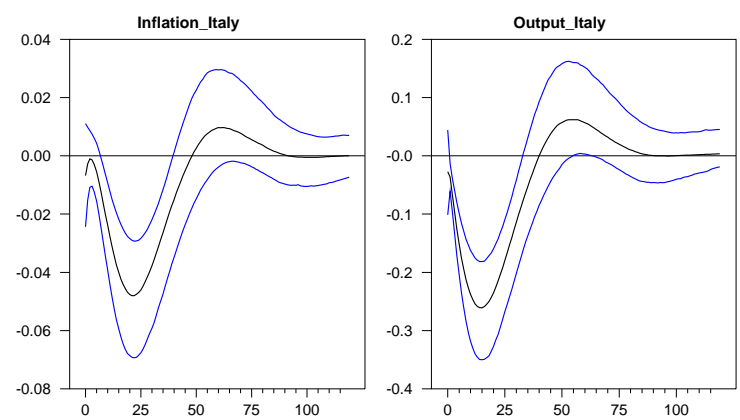

Responses to Monetary Policy Shock:Italy
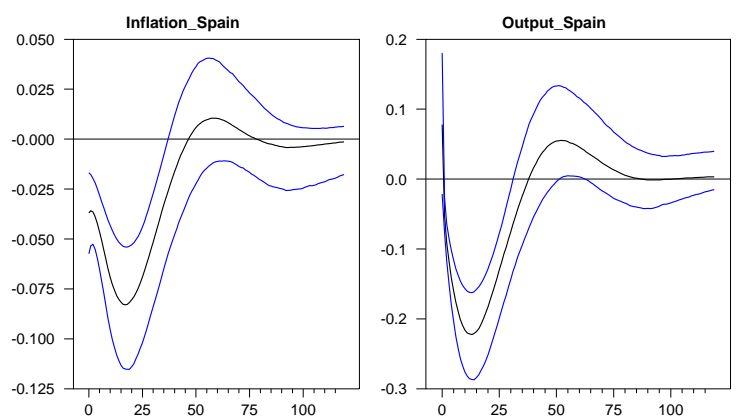

Responses to Monetary Policy Shock:Spain

FIGURE 2: Impulse-response functions for France, Germany, Italy and Spain: response of national output and inflation to a contractionary monetary policy shock. 

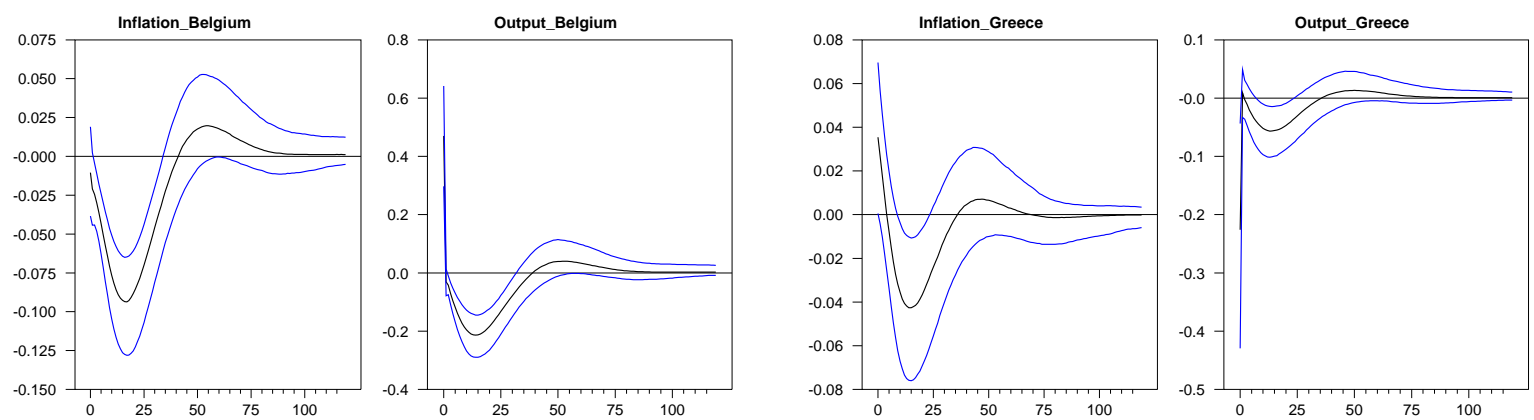

Responses to Monetary Policy Shock:Belgium

Responses to Monetary Policy Shock:Greece
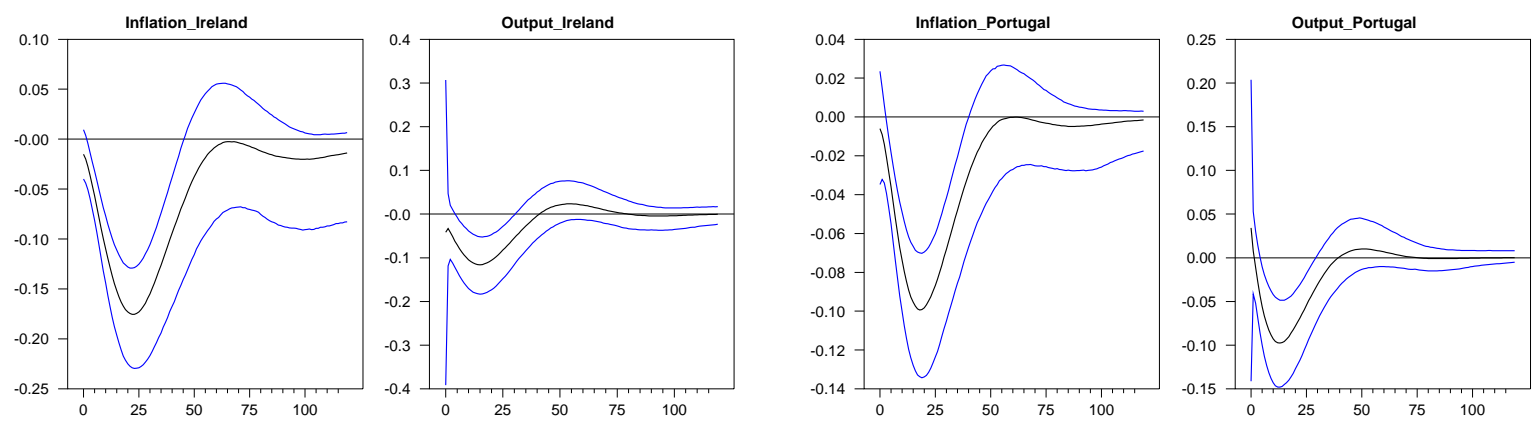

Responses to Monetary Policy Shock:Ireland

Responses to Monetary Policy Shock:Portugal

FIGURE 3: Impulse-response functions for Belgium, Greece, Ireland and Portugal: response of national output and inflation to a contractionary monetary policy shock. 


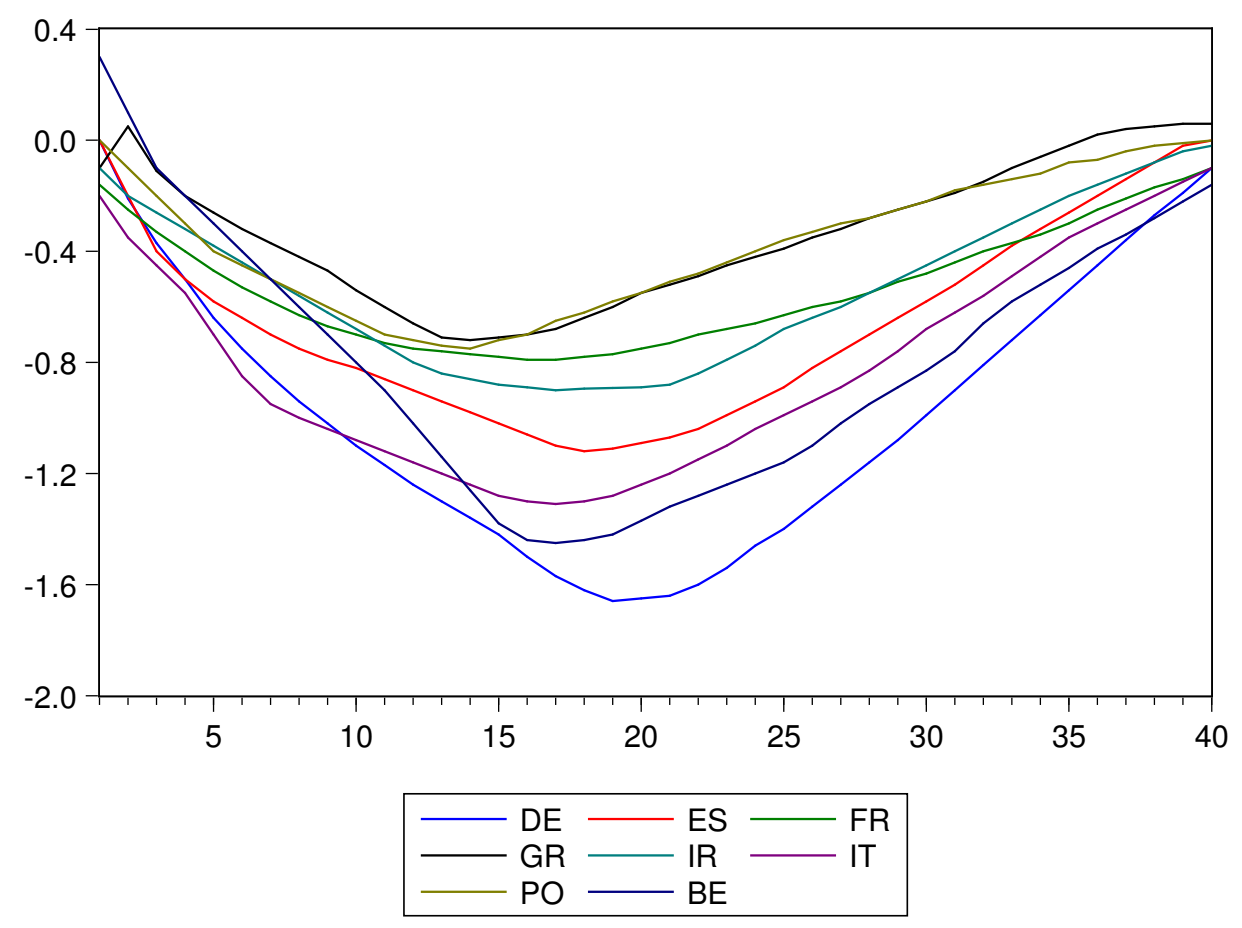

FIGURE 4: Collected responses of national ouput to the common, contractionary monetary policy shock. 

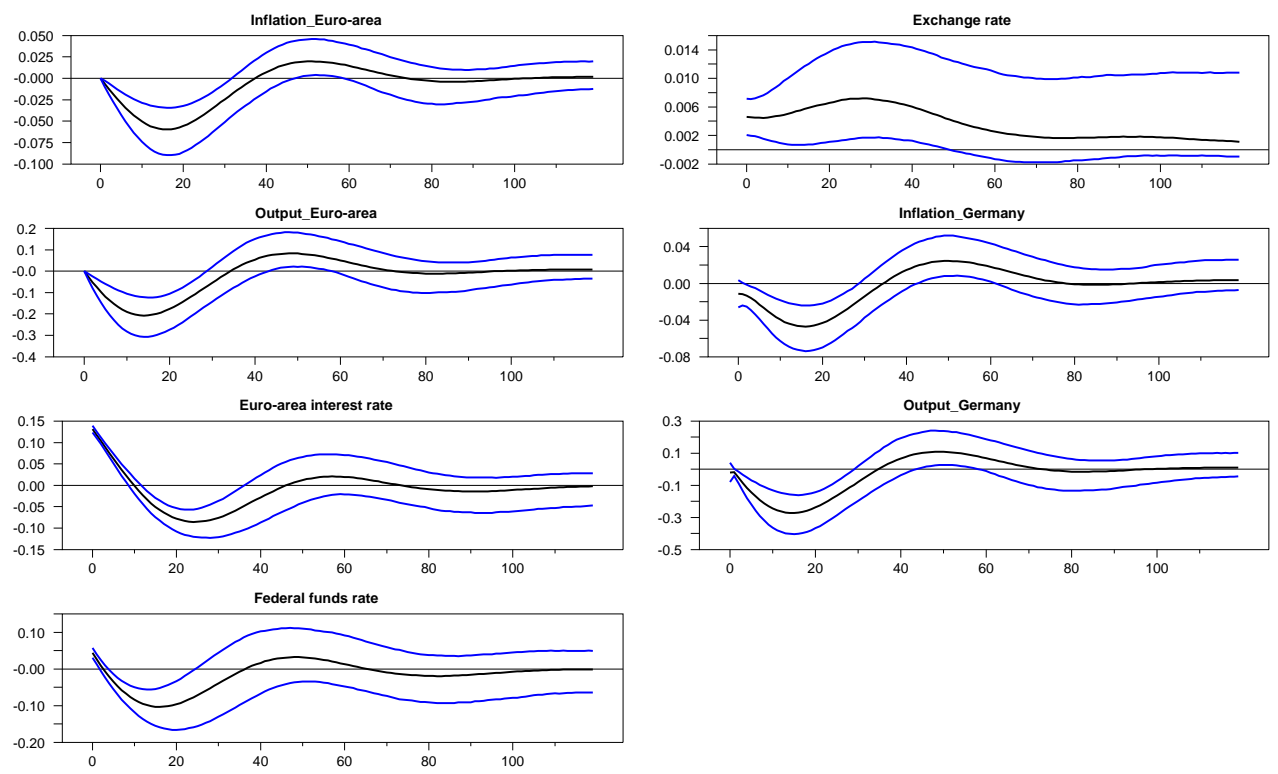

Responses to Euro-area Monetary Policy Shock

FIGURE 5: Response of Euro Area and German variables to a contractionary monetary policy shock: near-VAR model with two separate equations for Eonia and federal funds rate. 

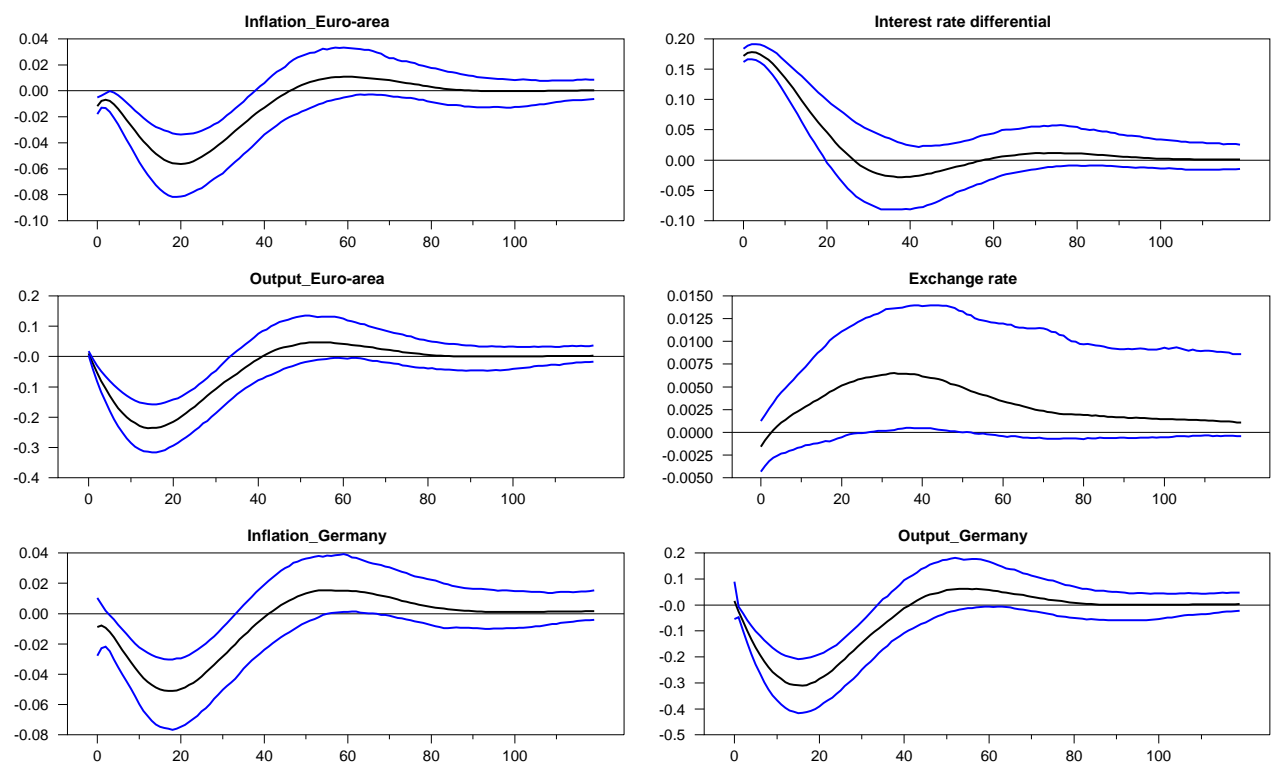

Responses to Monetary Policy Shock:Euro Area and Germany

FIGURE 6: Impulse-response functions for Euro Area and German variables: contractionary monetary policy shock identified by sign restrictions. 
Table 1. Measuring the co-movements between the cyclical component of national output and the cyclical component of Euro-area output.

\begin{tabular}{cccccccccccc}
\hline & \multicolumn{1}{c}{ Lag } & & \multicolumn{7}{c}{ Lead } \\
& 0 & 3 & 6 & 9 & 12 & 0 & 3 & 6 & 9 & 12 \\
\hline DE & .98 & .80 & .46 & .12 & -.17 & .98 & .74 & .38 & .04 & -.23 \\
& & & & & & & & & & \\
IT & .96 & .76 & .38 & .09 & -.28 & .96 & .79 & .46 & .10 & -.18 \\
& & & & & & & & & & \\
FR & .96 & .72 & .37 & .04 & -.21 & .96 & .77 & .44 & .08 & -.21 \\
& & & & & & & & & & \\
ES & .91 & .61 & .26 & -.04 & -.26 & .91 & .86 & .60 & .28 & -.06 \\
& & & & & & & & & & \\
BE & .82 & .60 & .33 & .05 & -.19 & .82 & .64 & .32 & -.01 & -.23 \\
& & & & & & & & & & \\
PT & .59 & .35 & .11 & -.07 & -.21 & .59 & .54 & .35 & .21 & .07 \\
& & & & & & & & & & \\
GR & .43 & .29 & .14 & .02 & -.08 & .43 & .34 & .18 & .09 & -.05 \\
& & & & & & & & & & \\
IR & .32 & .23 & .21 & .11 & -.08 & .32 & .20 & .15 & .03 & -.06 \\
\hline
\end{tabular}

Note: Cross correlations of national and Euro-area output, at various leads and lags, are reported for the period 1999: 1-2001:12. The cyclical component of output is obtained by applying to the series the Hodrick-Prescott filter. 
Table 2. Measuring the co-movements of inflation for a group of Euro-area countries.

\begin{tabular}{cccccccccccc}
\hline & \multicolumn{1}{c}{ Lag } & & \multicolumn{6}{c}{ Lead } \\
& 0 & 3 & 6 & 9 & 12 & 0 & 3 & 6 & 9 & 12 \\
\hline DE & .90 & .63 & .36 & .08 & -.21 & .90 & .69 & .43 & .14 & -.20 \\
& & & & & & & & & & \\
IT & .89 & .73 & .47 & .15 & -.15 & .89 & .59 & .27 & -.09 & -.36 \\
& & & & & & & & & & \\
FR & .94 & .66 & .32 &.-02 & -.33 & .94 & .70 & .39 &.-03 & -.31 \\
& & & & & & & & & & \\
ES & .88 & .62 & .30 & -.03 & -.31 & .88 & .72 & .46 & .15 & -.17 \\
& & & & & & & & & & \\
BE & .86 & .70 & .39 &.-01 & -.40 & .86 & .59 & .24 & -.09 & -.35 \\
& & & & & & & & & & \\
PT & .73 & .60 & .37 & .07 & -.22 & .73 & .62 & .41 & .21 & .01 \\
& & & & & & & & & & \\
GR & .65 & .44 & .10 & -.25 & -.53 & .65 & .52 & .38 & .15 & -.10 \\
& & & & & & & & & & \\
IR & .56 & .53 & .42 & .25 & .05 & .56 & .43 & .28 & .12 & -.03 \\
\hline
\end{tabular}

Note: Cross correlations of national and Euro-area inflation at various leads and lags are reported for the sample period $1999: 1-2001: 12$. 
Table 3. Estimated maximum effect of a monetary policy shock

\begin{tabular}{ccccccccc} 
& DE & FR & IT & ES & BE & GR & IR & PO \\
\hline Maximum effect & -1.82 & -.96 & -1.48 & -1.27 & -1.75 & -.94 & -.92 & -.81 \\
& & & & & & & & \\
Months & 17 & 16 & 16 & 19 & 17 & 1 & 21 & 14
\end{tabular}

Note: The first row reports the maximum responses of output in each country to a monetary policy shock. The size is a one percent increase in the differential between Eonia and the federal funds rate. The second row indicates the number of months required to reach the maximum effect. 
Table 4. Fraction of the forecast error variance of national output attributable to common Euro-area shocks at different horizons.

\begin{tabular}{|c|c|c|c|c|c|c|c|c|}
\hline Horizon & $\mathrm{DE}$ & FR & IT & ES & $\mathrm{BE}$ & GR & IR & $\mathrm{PO}$ \\
\hline 1 & 66.7 & 71.2 & 59.8 & 56.2 & 50.1 & 10.8 & 11.8 & 26.8 \\
\hline 12 & 94.2 & 88.9 & 88.2 & 77.4 & 75.7 & 28.1 & 18.5 & 42.4 \\
\hline 24 & 95.3 & 91.2 & 91.1 & 87.8 & 80.8 & 31.5 & 18.9 & 47.1 \\
\hline 36 & 96.1 & 92.1 & 94.0 & 85.6 & 86.4 & 32.6 & 22.1 & 48.3 \\
\hline 48 & 96.3 & 92.3 & 95.5 & 85.9 & 86.9 & 32.8 & 22.2 & 48.4 \\
\hline 60 & 96.3 & 92.3 & 96.2 & 86.1 & 88.1 & 33.4 & 23.5 & 48.6 \\
\hline 84 & 96.4 & 92.5 & 96.5 & 85.3 & 88.9 & 33.6 & 24.6 & 48.7 \\
\hline
\end{tabular}

Note: For each country, the total variance of the forecast error for output is computed and then decomposed in the part attributable to each structural shock (cf. formula [5]). The table presents the fraction of variability at various horizons which is due to the four Euro-area common macroeconomic shocks. 